\title{
TRANSPARENCY IN ELECTRONIC BUSINESS NEGOTIATIONS - EVIDENCE BASED ANALYSIS
}

\author{
DOI: 10.12776/QIP.V18I2.417
}

\author{
RADOSLAV DELINA
}

Received 7 September 2014, Revised 20 October 2014, Accepted 11 November 2014

\section{INTRODUCTION}

In current economy, where ICT plays a crucial role for being competitive and effective, businesses and especially small and medium-sized enterprises (SMEs) are facing higher pressures of flexibility and efficiency than ever before. The core business processes need to be supported by innovative but mainly effective ICT-based systems and tools. One of the crucial business success factors in new global and more transparent economy is cooperation and collaboration in whole business value chain on vertical but also on horizontal collaborative base. On the other hand, consumers are facing to new opportunities to find more suitable products and services using new ICT tools and network environments and services.

European Commission in its former strategies presents the importance of networked future where ICT plays crucial role in enterprise networking. This issue played and still plays significant role in IST related framework programmes objectives. According to these objectives, business network environment should be based on interoperability, standardization, trusted environment and multidisciplinary research in this area as crucial success factors. The interoperability of enterprise applications is especially important issue for the new collaborative business networks with self-organising, self-optimising and evolving features.

Although, ICT based networking is one of the main innovation topics in the field of Digital Society, only small number of researchers understand sensitivity of related issues, esp. transparency of market information inside the electronic network. This paper focuses on this critical determinant for achieving European objective of single e-market. 


\section{ECONOMIC CONSTRAINTS AND OPPORTUNITIES FOR ICT BASED ENTERPRISE NETWORKING}

Successful business examples mentioned above are still far away of the real enterprise networking concept supported by European Commission's strategies. Few efficient business networks based on really versatile functionalities and wide utility model are still rare and wide or single European ICT based SME's networks still absent. European initiative on European Single Electronic Market reflected necessary aspects for new networked economy, although the emphasize on platforms development and their market penetration get weak throughout past years and SMEs have still problem to find optimal suppliers or business partners and to utilize benefits of eCooperative and eCollaborative business networks. Is ICT based enterprise networking really worthy and how to manage networking evolution for the economy benefits?

First, we need to examine general economic benefits of ICT based enterprise networking or generally network effects in economy. Many studies deal with network effects and diffusion theories in innovations. Diffusion in our context is the adoption of ICT network services which implement us into the relevant network as an agent. Generally, the number of new adopters in a certain period of time is usually modelled as the proportion of the group of market participants that have not yet adopted the innovation (Weitzel et al., 2003). Most of the traditional approaches focus on the relationship between the rate of diffusion and the number of potential adopters.

For modelling the diffusion of network effect products, three areas of deficit are eminent: critical mass phenomena are not sufficiently analysed, real life diffusion processes cannot be explained, too, and the interaction of potential adopters within their socio-economic environment is not sufficiently elaborated (Schoder, 1995).

Of course, the innovations diffusion models and strategies are important, but to examine the way how to adopt without proper understanding of "what will happen" is dangerous.

Network effect literature is generally based on the neo-classical assumptions where all agents not only know their own action space and utility function but likewise have a complete and realistic model of all the other agents' current allocation, action spaces and utility functions as well. In a neo-classical "exchange economy" this assumption may lead to a unique and Pareto-optimal equilibrium, but only in the case of no network externalities or indivisibilities (Weitzel et al., 2003).

But real business and social world is more complex and suffer from high level of uncertainty and heterogeneity in economic environments which bounds effective decision making of socio-economic agents (Doucek, 2004). Inefficiencies in traditional theories leaded Weitzel et al. (2003) to propose Interdisciplinary Network Theory, where a necessary condition for developing an operable view 
on networks was the one, that can be accepted by economists as well as researchers from social sciences is to incorporate the concepts of bounded rationality, uncertainty and incomplete information and social embeddedness. These assumptions are in line with our mentioned barriers and character of ICT based business networks. Bounded rationality is nowadays generally accepted assumption which complicated economic and social analysis. Although, game theory and other behavioural theories have significantly contributed to better understanding of bounded rationality and its impact. Uncertainty and incomplete information is in my eyes more significant problem related to ICT based business networks which definitely deals mainly with increased transparency and efficiency (which is based more on specific ICT services as networks as a infrastructure). In the incomplete information situation, uncertainty increases the cost of transaction or searching/sourcing. Such an externality harms economic environment and suitable IT networking services can significantly contribute to better business environment and trust within business relations. Increased transparency deals with uncovering market and market information by ICT and ICT based networks to all participants (Janke, 2011). Generally, it should lead to market and price transparency where the transparency refers to the level of current trade (e.g. price) information accessible to participants by market makers (Ozcelik and Ozdemir, 2011).

When we consider size of the network we can accept the assumption that the increased number of network participants (size of the network), the increased level of market transparency. Nowadays we know only fragmented market with number of e-marketplaces. But through acquisitions and e-marketplaces and business networks interoperability, the single business network as a digital form of traditional market is possible. Of course, it requires some support by policy makers, ERP or legacy system providers and acceptance of companies. Within the single e-market, transparency will rapidly grow but what will happen with the prices, antitrust issues or wealth distribution?

\subsection{Market and price transparency in B2B commerce}

Increase in transparency in market and across global supply chains is crucial issue for most important economics from U.S. to European countries. Increasing market transparency contributes to price tracking and readability and results in higher market efficiency. This issue affects also Business-to-Business (B2B) exchange markets or business networks in general, which aggregate buyers and sellers around the world, causing the decrease in information asymmetry (Hansen et al., 2001). According to Zhu (2004), transparency becomes one of the key features that distinguish digital exchanges from traditional markets. On vertical marketplaces suppliers can see who is selling which parts, at what prices, and in what quantities. In many other exchanges using reverse auctions, participants see all competitors and their bids, historical behaviour and general market information (Phama et al., 2014; Schoenherr and Mabert, 2007). 
Transparency is generally considered as important factor for commercial profit (Granados, 2008) and also government quality (Grzebyk, 2010). Price transparency is considered also by OECD as important issue for increasing benefits of buyers unless it results in considerably increased risks of collusion among sellers. One way to describe price transparency is to refer to the costs in time and money required to discover actual transactions prices. The lower are the costs, the more transparent is the market. A certain level of price transparency is necessary for competition and to be able to compare prices. Some other studies are measuring level of transparency directly on B2B exchanges as a level of eservices providing tools for more transparent bidding and negotiation as for example reverse auctions (Soh, Markus and Goh, 2006; Carter and Stevens, 2007). According to OECD (2001), under certain conditions, increased price transparency can in traditional market significantly increase the probabilities of conscious parallelism and anti-competitive co-ordination. In a sufficiently concentrated market, the process could start by one seller simply raising its price and watching to see if others follow. The price leader's risks in doing that are lower when sellers are quickly and accurately informed of price changes, especially if buyers are not. But this situation is not common for pure electronic market, where price information for buyers is almost perfect. In addition to facilitating conscious parallelism, increased price transparency could also encourage tacit or outright collusion by generally making it easier for cooperating firms to detect and therefore punish deviating firms. The situation in electronic market is more effective as broadness and distance free character of information in electronic channels support multi-cooperative consortium creation which reduces parallelism from this point of view. Some authors consider trust as a key factor for efficient transparency (Dorčák, Pollák and Szabo, 2014; Szabo, Dorcák, Ferencz, 2013).

Summarization of negative aspects of transparency presented by another studies (Soh, Markus and Goh, 2006; Zhu, 2004; Ozcelik and Ozdemir, 2011; Gu and Hehenkamp, 2010) are as follows:

- High price transparency negatively affects sellers what can be solved through compensatory benefits or differentiated strategies. As e-markets are place for both side of players as buyers and suppliers, price transparency should be managed in optimal way between them.

- In the case of fewer sellers and highly differentiated products high price transparency is unlikely.

- Certain types of companies (e.g., high-cost suppliers of substitute products) will lack the incentives to join the exchange as information transparency hurts more than helps them. In contrast to the widely held belief about its benefits (the so-called information transparency hypothesis.

- Price and market transparency is sometimes in contradiction to anonymity and confidentiality requests of participants. 
- Too much market transparency harms competition when entry becomes less profitable and hence less likely. As a consequence, market breakdown occurs more and oligopoly less often, both of which effects reduce welfare. As the main result of $\mathrm{Gu}$ and Hehenkamp (2010) shows, the welfare-diminishing effects dominate when markets are sufficiently transparent.

Generally, price and market transparency is very difficult to measure and most of studies rely on game theories and strong assumptions in their models which often are in contradiction with many real situations. But the message of these studies is logical and clear: on one hand price and market transparency have positive impact on prices and quality for buyers, on the other hand it is the barrier for seller to enter the e-market. Market transparency needs to accept some level of confidentiality in some cases.

\section{RESEARCH METHODOLOGY}

To examine the impact of transparency in electronic business environment, real data from reverse auctions were applied. Reverse auction as electronic tool is considered as a service partially substituting real competitive environment. Together, electronic reverse auction provide the possibility to set up different levels of transparency within the negotiation process.

Research working question within this paper is formulated as follows:

\section{Has higher transparency within procurement negotiation process positive impact on winner price?}

For transparency impact examination, we can consider two ways:

- Compare sealed bid auction and English reverse auction involving an iterative process of decreasing price with competing sellers. Sealed bid auction is considered as anonymous price and market information environment for other bidders. English reverse auction is considered as transparent environment with several level of transparency set up.

- Different transparency level in English reverse auction, where auction negotiation environment has several option for visibility of information for auction participants, e.g. visible different combination of information from price, name of participant, order, final winner sum, partial prices for each item within one auction, etc.

Real data from reverse auction systems were aggregated from several electronic reverse auction realized in Slovakia. Description of data sample is provided in Table 1. 
Table 1 - Sample description

\begin{tabular}{l|l|l|l}
\hline Number of purchasers & Number of auctions & $\begin{array}{l}\text { Number of sealed bid } \\
\text { auctions }\end{array}$ & $\begin{array}{l}\text { Number of English } \\
\text { reverse auctions }\end{array}$ \\
\hline 21 & 1696 & 752 & 944
\end{tabular}

\section{RESEARCH RESULTS}

The dataset extracted from reverse auction software was processed and used for statistical examination. Evidenced based analysis in this field has several circumstances. First, economic indicators as savings are not so easy to be calculated. The problem is which price can be compared to winning price. If first bid or price from previous business transaction. There are two possible ways how to calculate savings within our reverse auction. One is focused on savings calculated with "benchmark" price, which is price stated by purchasing manager on behalf of historical transaction or accessible general catalogue (Savings_C). Second option is to use first bid (Savings_I). It means, the calculation of savings in both cases is as follows:

Savings_C $(\%)=($ benchmark price - winning price $) * 100 /$ benchmark price

Savings_I $(\%)=($ first price - winning price $) * 100 /$ first price

For comparison of sealed bid auction and English reverse auction, dataset was divided into two samples according to the type of auction:

Type 2: data from sealed bid auction

Type 3: data from English reverse auction

As it was explained in methodology chapter, sealed bid auction is considered as anonymous transaction and English reverse auction as transparent transaction. According to promoted reverse auction benefits, more transparent solutions should bring higher savings. On this formulation, business models of reverse auction SW solutions are set up.

As we see from Figure 1, the mean of savings is surprisingly better within sealed bid auction with higher standard deviation. It shows, that current promotion of reverse auction is not so correct or that purchasers are not able to manage auction processes effectively. 


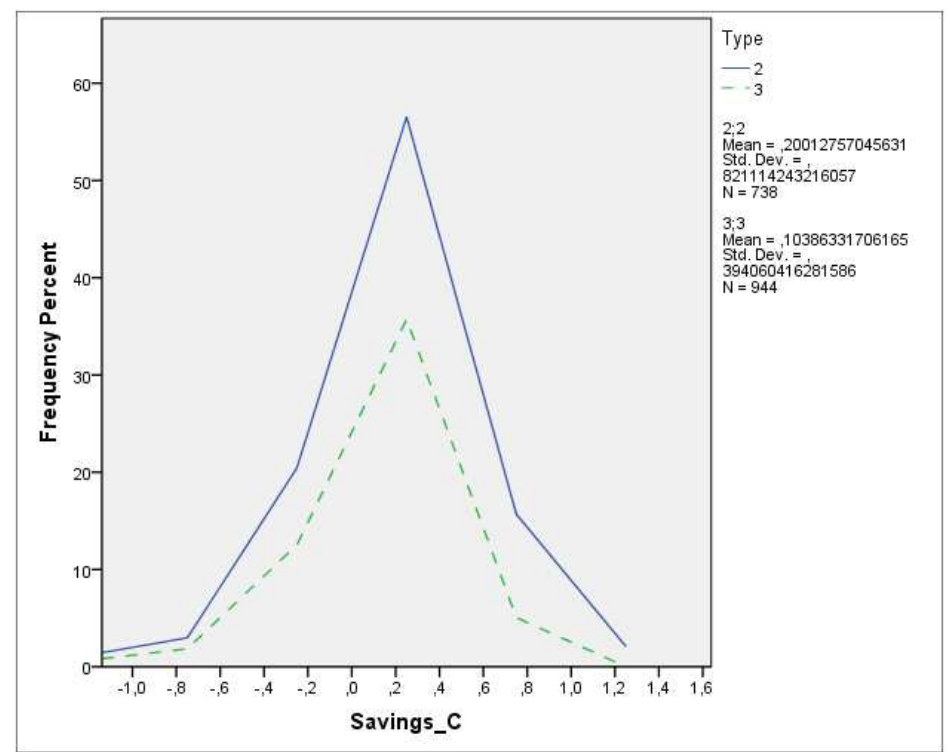

Figure 1 - Savings from sealed bid auctions (2) and reverse auctions (3)

Together, for better presentation, cumulative probability functions for both types of auctions is provided in Figure 2. It shows, that sealed bid auction achieves higher savings within the same level of probability or frequency.

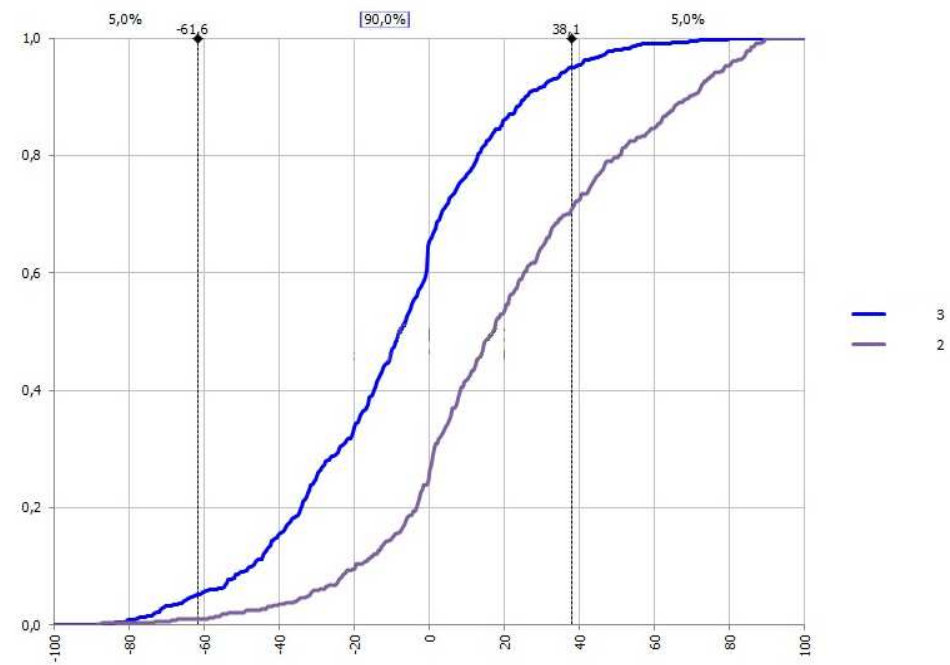

Figure 2 - Cumulative distribution of savings from sealed bid auctions (2) and reverse auctions (3)

As second analysis, the English reverse auction data was analysed more deeply. It was focused on possibility of reverse auction parametrization in the field of information visibility on negotiation screen. This auction solution allows to 
publish several types of information from order (ranking), name of participant, his actual price within negotiation, his total price for all items in one auction, etc. The transparency level was calculated by sum of possible setting of auction process (from 1-7), where 1 is lowest option of transparency and 7 is absolutely transparent information in the negotiation. First correlation analysis shows, that higher transparency has rather negative impact on the price probability like current promotions (Table 2).

Table 2 - Correlation table between transparency and price savings

\begin{tabular}{cl|r|r}
\hline & & Savings_C & Savings_I \\
\hline Transparency & Pearson Correlation & -.028 & $-.150^{* * *}$ \\
& Sig. (2-tailed) & .413 & .000 \\
$\mathrm{~N}$ & 882 & 882 \\
\cline { 2 - 4 } & Kendall's tau_b & -.036 & $-.100^{* * *}$ \\
Sig. (2-tailed) & .173 & .000 \\
$\mathrm{~N}$ & 882 & 882 \\
\hline Spearman's rho & -.047 & $-.127^{* * *}$ \\
Sig. (2-tailed) & .164 & .000 \\
$\mathrm{~N}$ & 882 & 882 \\
\hline
\end{tabular}

**. Correlation is significant at the 0.01 level (2-tailed).

To see distribution of each saving achieved in English reverse auction according to different level of transparency set up, following Figure 3 is presented.
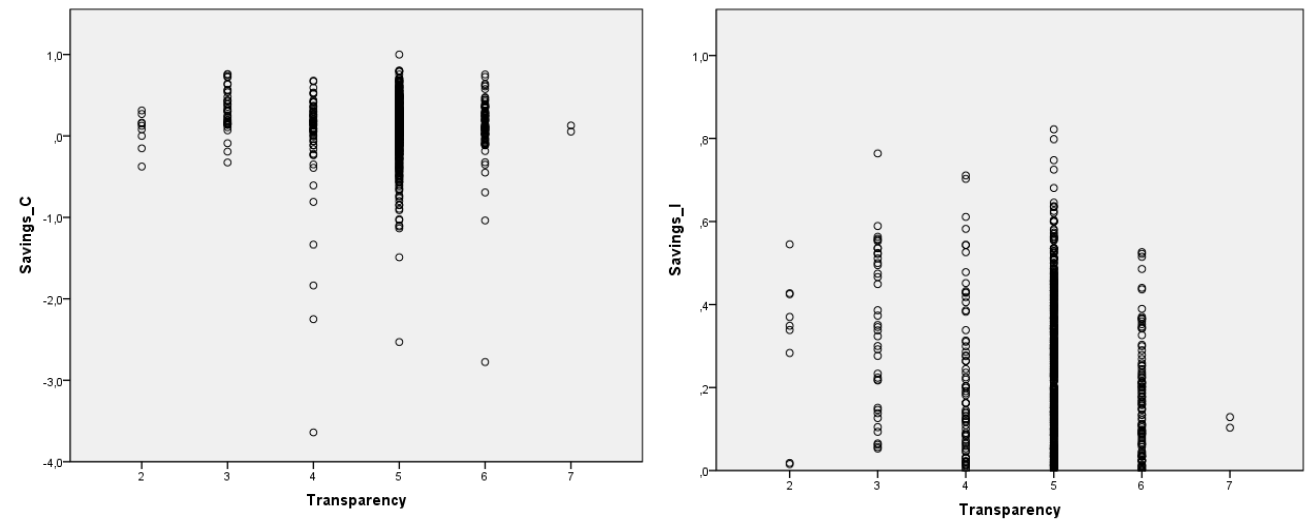

Figure 3 - Savings according to different level of transparency 


\section{CONCLUSION}

From research results based on data from real environment, we can see, that transparency is not so clear dogma as it is presented in most of scientific papers or commercial proclamations. We believe, that transparency is much more complex phenomena and in many situations, anonymity can push on auction participants to make more irrational decisions submitting better prices or utility for purchasers. On the other hand, our preliminary analysis shows, that in some specific cases (e.g. when higher number of participants exists), transparency can bring positive impact on negotiated prices.

These results call for wider research with more extensive datasets from different countries to compare cultural or sectorial differences.

\section{ACKNOWLEDGEMENT}

This work was supported by Scientific Grant Agency VEGA of Slovak Republic within the grant No. 1/0855/14 "Determinants of efficient purchasing supported by electronic solutions".

\section{REFERENCES}

Carter, C.R. and Stevens, C.K., 2007. Electronic reverse auction configuration and its impact on buyer price and supplier perceptions of opportunism: A laboratory experiment. Journal of Operations Management, 25(5), 31 August 2007, pp.1035-1054.

Dorčák, P., Pollák, F. and Szabo, S., 2014. Analysis of the possibilities of improving an online reputation of public institutions. In: IDIMT 2014: Networking Societies - Cooperation and Conflict, 22nd Interdisciplinary Information Management Talks, Sept. 10-12, 2014, Podebrady, Czech Republic, pp. $275-282$

Doucek, P., 2004. E-Society - Perspectives and Risks for European Integration. In HOFER, C. - CHROUST, G. (ed.). IDIMT-2004. Linz: Trauner Verlag universitat, 2004, pp.35-42. ISBN 3-85487-665-3.

Granados, N., Gupta, A. and Kauffman, R.J., 2008. Designing online selling mechanisms: Transparency levels and prices. Decision Support Systems, 45(4), November 2008, pp.729-745.

Grzebyk M., 2010. Determinants influencing the competitiveness of local government units. In: Ekonomicky rozvoj a management regionu, Hradec Kralove, 2- 3 February, 2010, pp.95-98, ISBN 978-80-7435-040-5.

Gu, Y., Hehenkamp, B., 2010. The Inefficiency of MarketTransparency - A Model with Endogenous Entry. BeiträgezurJahrestagung des VereinsfürSocialpolitik 2010: Ökonomie der Familie - Session: Oligopolistic 
Competition and NetworkFormation, No. F9-V2. [PDF] Available at: <http://hdl.handle.net/10419/37416>.

Hansen, M., Mathews, B., Mosconi, B. and Sankaran, V., 2001. A buyer's guide to B-to-B markets. McKinsey Quarterly, 2, pp.33-35.

Janke, F., 2011. The Use of Hidden Data in Electronic Business Networks: Benchmark and Network Performance Indicators. In: IDIMT-2011: Interdisciplinarity in Complex Systems: 19th Interdisciplinary Information Management Talks: 7. - 9.9.2011, Jindřichův Hradec, pp.341-348, ISBN 978-385499-873-0.

OECD, 2001. Price Transparency. Policy roundtables. DAFFE/CLP(2001)22. Available at: 〈http://www.oecd.org/dataoecd/52/63/2535975.pdf>.

Ozcelik, Y. and Ozdemir, Z. D., 2011. Market Transparency in Business-toBusiness e-Commerce: A Simulation Analysis. International Journal of EBusiness Research (IJEBR), 7(4), pp.62-78.

Phama, L., Teichc, J., Walleniusd, H. and Wallenius, J., 2014. Multi-attribute online reverse auctions: Recent research trends. European Journal of Operational Research, 7 October 2014, [online] Available at: <http://dx.doi.org/10.1016/j.ejor.2014.08.043>.

Schoder, D., 1995. Erfolg und MißerfolgtelematischerInnovationen, Wiesbaden: Deutscher Universitäts- Verlag.

Schoenherr, T. and Mabert, V.A., 2007. Online reverse auctions: Common myths versus evolving reality. Business Horizons, 50(5), September-October 2007, pp.373-384.

Soh, Ch., Markus, M. L. and Goh, Kim H., 2006. Electronic Marketplaces and Price Transparency: Strategy, Information Technology, and Success. MIS Quarterly, 30(3), pp.705-723.

Szabo, S., Dorcák, P. and Ferencz, V., 2013. The significance of global market data for smart E-Procurement processes. In: IDIMT 2013 - Information Technology Human Values, Innovation and Economy, 21st Interdisciplinary Information Management Talks, Sept. 11-13, 2013, Prague, Czech Republic. pp.217-224.

Weitzel, T., Wendt, O. and König, W., 2003. Towards an Interdisciplinary Theory of Networks. In: Proceedings of the 11th European Conference on Information Systems (ECIS). Naples, Italy, 2003.

Zhu, K., 2004. Information Transparency of Business-to-BusinessElectronic Markets: A Game-Theoretic Analysis. Management Science, 50(5), May 2004, pp.670-685. 


\section{ABOUT THE AUTHOR}

Radoslav Delina, PhD., Assoc. prof. at the Faculty of Economics Technical University of Kosice. He is member of EU RTD Evaluation Network and member of working group for Model Grant Agreement under Horizon2020 under DG Research and Innovation. He is national expert and correspondent for eBusinessw@tch - the Initiative of European Commission and other initiatives as eWork, Construst, e-Skills For The 21st Century, etc. He is focusing his activities on the research in the field of Information Society and the information and communication technology (ICT) impact on different socio-economic domains. Radoslav participated and coordinated number of international research and educational projects $(\mathrm{FPx}, \mathrm{CE} \mathrm{OP}, \mathrm{LdV}, \ldots)$ in the field of electronic networking, eCooperation, eServices. e-mail: radoslav.delina@tuke.sk 